\title{
Metsovo Lung: A Story of Episteme, Techne, and Phronesis
}

\author{
Vasilios Tzilas Argyris Tzouvelekis Demosthenes Bouros \\ 1st Respiratory Medicine Department, "Sotiria" Chest Diseases Hospital, Medical School, National and \\ Kapodistrian University of Athens, Athens, Greece
}

Metsovo Lung is a classical world-known example of domestic asbestos exposure that led to an "epidemic" of pleural calcifications and malignant pleural mesothelioma. About 40 years ago, the prevalence of pleural calcifications on chest X-rays was almost $50 \%$ with increasing rates at older ages ( $81 \%$ above the age of 70 [1]). Between 1981 and 1985, 7 patients from the Metsovo area, with a population of 5,000, were diagnosed with pleural malignant mesothelioma. The incidence of pleural mesothelioma in the area of Metsovo was 280 times greater than the expected incidence of $1 / 1,000,000 /$ year [2]. The source of asbestos exposure was the white soil (luto) which the residents of Metsovo (Metsovites) used to whitewash their houses during the last century. Luto contained tremolite (a member of the amphibole group of silicate minerals). Preparation of luto involved crushing it to a thin powder that resulted in the release to ambient air of more than 200 asbestos fibers $/ \mathrm{cm}^{3}$. This way, the whole family (including children) was domestically exposed to asbestos. Oryctological studies confirmed that tremolite fibers contained in luto were identical to tremolite fibers found in transbronchial biopsies from Metsovites [3, 4].

The domestic use of luto has been abandoned since the mid-eighties because the residents moved on to modern, user-friendly whitewashing materials and not because it was considered dangerous at that time. In this issue of Respiration, Gogali et al. [5] aimed to investigate whether the residents in the region of Metsovo were still exposed

\section{KARGER}

() 2017 S. Karger AG, Basel

E-Mail karger@karger.com

www.karger.com/res to alternative sources of asbestos after abandoning luto as whitewashing material.

Asbestos exposure was based on two elements: the presence of pleural plaques on chest computed tomography and the presence of asbestos bodies in bronchoalveolar lavage (BAL). In the absence of both elements, no clinically significant exposure to asbestos was inferred. Gogali et al. used an active surveillance group that consisted of Metsovites born between 1960 and 1980 with recruitment taking place between 2007 and the end of 2011. The rationale for choosing this particular age window was that the „latent period” for the development of pleural plaques recognizable with chest CT is about 30 years, thus excluding residents born after 1980 from the study. It was deemed unnecessary to examine residents born before 1960 because the domestic use of luto at that time was actually universal in the area of Metsovo. Hence, exposure, even if not reported, could not be reliably excluded. The active surveillance group comprised of 36 Metsovites; 22 were evaluated prospectively while the remaining 14 retrospectively. Exposure to luto was reported by 5 individuals (3 during toddler years and 2 until adolescence). Chest CT data were available from all the individuals in the active surveillance group. Eight individuals gave their consent to undergo BAL. Data from previous studies regarding Metsovo Lung, as well as chest CTs of older Metsovites at the time of the current study, served as a comparison group. 
No pleural calcifications were observed in the active surveillance group with the exception of 2 individuals that reported exposure to luto until adolescence. This is in stark contrast with a previous study in the area of Metsovo where even in the absence of visible calcified pleural plaques on chest X-ray, they were observed in all individuals when they were examined with chest CT [6]. Regarding BAL, all individuals from the active surveillance group were negative for the presence of asbestos bodies. This is also in direct contrast to previous studies performed by the same group in Metsovo when luto was still in use. In these studies, in exposed individuals of the same age as the active surveillance group, asbestos bodies were found in 6 out of 7 , while asbestos bodies were found in 54 out of 75 individuals, regardless of age.

The above data are totally compatible with the conclusion that tremolite-containing luto was the only source of asbestos exposure and following the discontinuation of its use, the Metsovites are no longer exposed to any asbestos as it is depicted by the paucity of calcified pleural plaques and asbestos fibers in BAL in younger individuals aged 30 to 50 years. The above conclusion is further supported by the fact that the age distribution of calcified pleural plaques since the eighties has shifted towards the elder population in Metsovo. Moreover, only 2 cases of malignant pleural mesothelioma have been described in residents of the Metsovo area after 2000 (the last in 2005), further supporting the conclusion that luto was the exclusive source of asbestos exposure [7].
This paper should not be viewed individually, but in the entirety of the Metsovo Lung story. It actually represents another chapter (and probably the last) in this intriguing story. The presence of pleural calcifications in Metsovites was erroneously considered for decades as the result of healed tuberculous pleurisy with no evidence of asbestos exposure [8]. It required courage to doubt long-established views, alongside with systematic research and logical reasoning by professor Constantopoulos et al. for the Metsovo mystery to be unraveled [8, 9]. Metsovo Lung is a classic example reflecting the application of science according to ancient Greek philosopher Aristotle. According to Aristotle as described in the Nichomachean Ethics, there are three types of knowledge: Episteme, Techne, and Phronesis. Episteme refers to theoretical knowledge, Techne (Art) to practical application of theory, and Phronesis to the combination of theory and practice in the context of practical reasoning. In Metsovo Lung, all three aspects of knowledge were combined in harmony. There was Episteme (theoretical knowledge of the deleterious effects of asbestos), Techne (performance of BAL and oryctological studies), and Phronesis (the combination of the above under the prism of practical reasoning resulting in the recognition of luto as the exclusive source of asbestos exposure and in taking all appropriate actions for the well-being of society). We are glad to see that the Metsovo Lung story has a happy ending.

\section{References}

1 Constantopoulos SH, Goudevenos JA, Saratzis NA, et al: Metsovo Lung: pleural calcifications and restrictive lung function in North-Western Greece; environmental exposure to mineral fiber as etiology. Environ Res 1985;38:319-331.

2 Constantopoulos SH, Malamou-Mitsi V, Goudevenos JA, et al: High incidence of malignant pleural mesothelioma in neighbouring villages of Northwest Greece. Respiration 1987;51:266-271.
3 Langer AM, Nolan RP, Constantopoulos SH, et al: Association of Metsovo Lung and pleural mesothelioma with exposure to tremolitecontaining whitewash. Lancet 1987;25:965967.

4 Constantopoulos SH, Langer AM, Saratzis N, et al: Regional findings in Metsovo Lung. Lancet 1987;2:452-453.

5 Gogali A, Ntzani EE, Manda-Stachouli C, et al: Evidence suggesting end of universal domestic asbestos exposure in Metsovo, NW Greece.Respiration,DOI:10.1159/000480151.
6 Constantopoulos SH, Saratzis NA, Goudevenos JA, et al: Tremolite white-washing and pleural calcifications. Chest 1987;92:709-712.

7 Gogali A, Manda-Stachouli C, Ntzani EE, et al: Malignant mesothelioma in Metsovo, Greece, from domestic use of asbestos: 30 years later. Eur Res J 2012;39:1-2.

8 Bouros D: Metsovo Lung. Case closed. Pneumon 2014;27(suppl 1):26.

9 Constantopoulos SH: Metsovo Lung. A medical detective story with a happy ending. Pneumon 2014;27(suppl 1):31-41. 